\title{
Provision of services to asylum seekers. Are there lessons from the experience with Kosovan refugees?
}

\author{
S Ghebrehewet, M Regan, L Benons, J Knowles
}

J Epidemiol Community Health 2002;56:223-226

Arrangements that were made to receive and support Kosovan refugees in the United Kingdom should be applied to asylum seekers arriving in the country.

$\mathrm{S}$ imilar social circumstances of immigrants may trigger dissimilar political responses and levels of resources from host countries. Necessary political commitment and provision of adequate resources by the UK government made it possible to provide a more formalised service provision and coordinated response for the Kosovan Refugees. However, it is becoming increasingly difficult to provide basic services for asylum seekers sent to different parts of the country following the dispersal scheme under the Immigration and Asylum Act 1999. ${ }^{1}$ In this paper we discuss some of the support arrangements available to asylum seekers, the problems encountered by primary care providers and health authorities, and the lessons learnt from arrangements for Kosovan refugees. It is concluded that similar, arrangements to those established for the Kosovan refugees should be put in place for asylum seekers, and some recommendations are made on how this could be done.

\section{THE PROVISION OF SERVICES TO ASYLUM SEEKERS}

Over 70000 asylum applications were made in 1999 , and current estimates suggest that over $85 \%$ of asylum seekers and refugees live in London. ${ }^{2}$ The Immigration and Asylum Act 1999 gave the UK government the power to disperse existing and new asylum seekers around the country. The government believes this is necessary as a means of relieving the pressure on local authorities in London and the south east arising from a large number of asylum applications. The first phase is the period from April 2000 to August 2000 when port of entry applicants will be dispersed across the country. The second phase is from September 2000 onwards when both (at port of entry and in-country applicants) will be subject to dispersal arrangements. The third phase is the dispersal of all existing asylum seekers from London and south east. Figures 1 and 2 show the previous and current support arrangements for asylum seekers respectively.

\section{CURRENT SERVICE PROVISION FOR ASYLUM SEEKERS IN LIVERPOOL}

During the first phase of the implementation of the Immigration and Asylum Act 1999 (April 2000 to August 2000), it is estimated that
Liverpool has received approximately 1000 asylum seekers. The estimate is based on the number of asylum seekers known to the local authority, Refugee Action, and other service providers. The above figure does not include asylum seekers who came to the city earlier through separate negotiations between individual London councils and private landlords (about 1000).

All refugees, regardless of their status, are entitled to use the full range of NHS services free of charge. ${ }^{4}$ This includes the right to register with a general practitioner (GP), dentist or optician and to receive NHS prescriptions and specialist care. Currently, in Liverpool, there are four ways in which asylum seekers are registering with primary care.

(1) Consortium-asylum seekers coming via the consortium are registering with the on-site associate physician of a neighbouring general practice. (A consortium model, developed by the government and the Local Government Association (LGA), is the vehicle to manage dispersal locally. Eight local authority led regional consortiums in England and one each in Scotland and Wales were established prior to April 2000).

(2) Allocation by the Health Authority-the health authority receives notification directly from the National Asylum Support Services (NASS) Directorate of the Home Office, or in some cases, Refugee Action. No indication of language spoken is given on these notifications. In some cases important information such as date of birth is also missing. The health authority allocates these people to a GP practice.

(3) Asylum seekers arriving with a letter stating the location of the nearest GP-this advice could have been provide by one or more private accommodation providers.

(4) Asylum seekers presenting to primary care services.

The major problems facing service providers, in particular primary care and health authorities can be summarised under five themes:

(1) Lack of information on the total number of asylum seekers within the district.

This problem arose when individual local authorities from London and south east were able to negotiate and make arrangements with individual landlords to accommodate asylum seekers. Asylum seekers can also make their own accommodation arrangements, which further compounds the problem and makes planning services more difficult.

(3) Lack of prior notification about the arrival of asylum seekers.

There is no procedure in place to notify relevant organisations prior to the arrival of asylum seekers. The NASS is still sending asylum seekers 


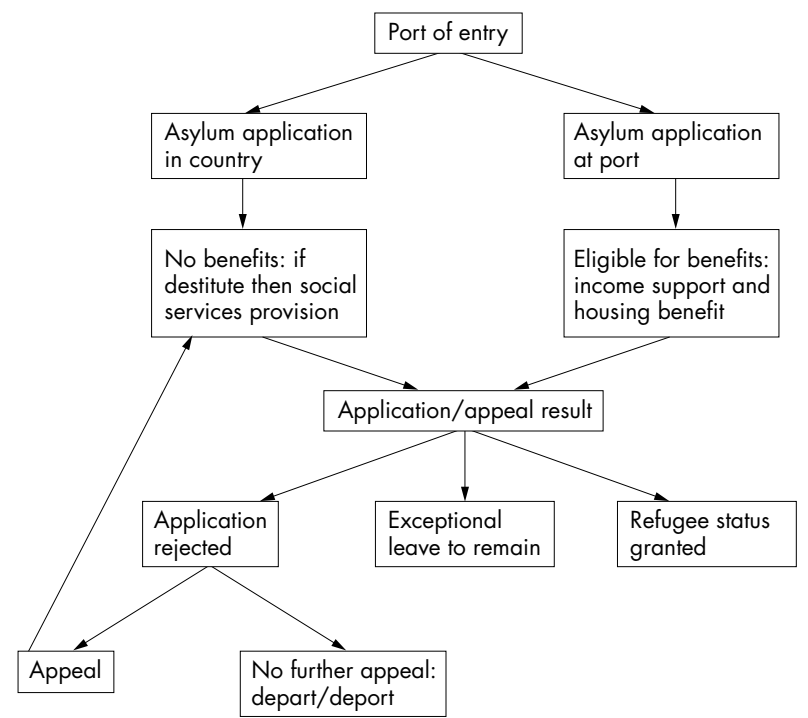

Figure 1 Previous (1996) system ${ }^{3}$

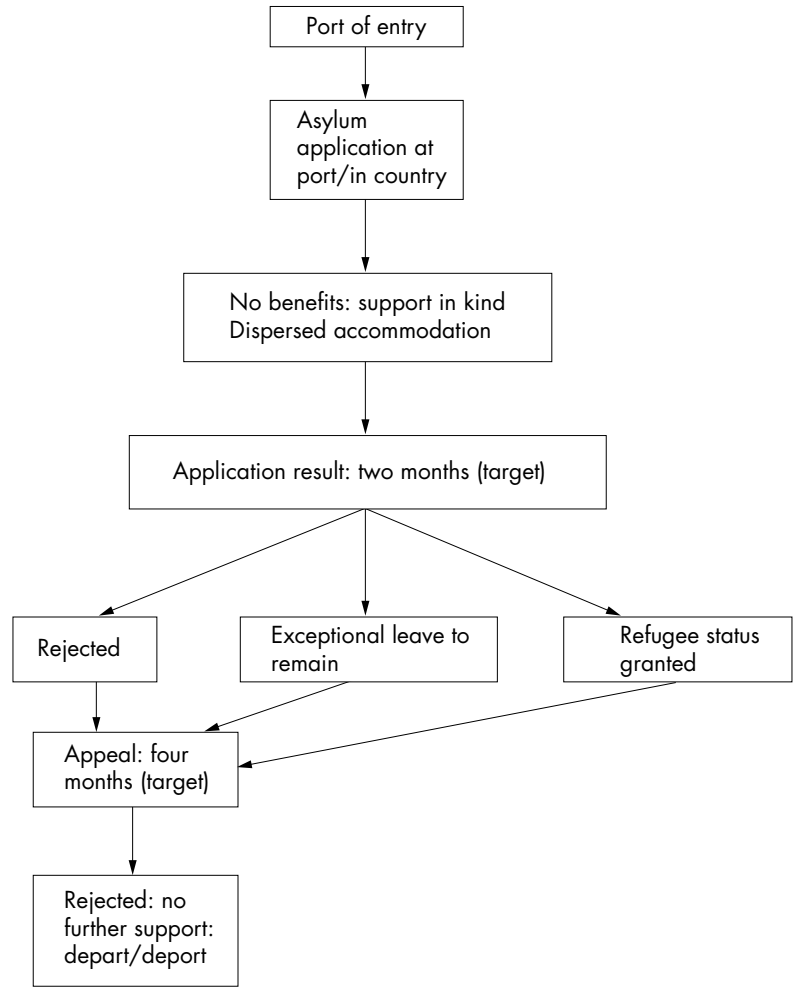

Figure 2 Current (fairer, faster, firmer/1999Act) system. (1) A person, who applies for asylum either at the port of entry or at the Home Office, is officially known as an "asylum seeker". (2) Exceptional leave to remain (ELR) is given when the person does not qualify for refugee status but allows him/her to stay on a temporary basis. ELR is given on the basis of personal circumstances or because of the situation in a particular country such as war and famine.

through other routes, mainly private accommodation. There is hope that this will improve once the contract between the NASS and regional consortium to provide accommodation and services is finalised.

(3) Lack of additional resources for health care.

The workload has increased tremendously in certain areas of the city, particularly in primary care, but no additional money is allocated to meet the health needs of the asylum seekers. For example, between 20 April 2000 and 22 August
Table 1 Allocation of asylum seekers to general practices in Liverpool $(20$ April-22 August 2000)

\begin{tabular}{ll}
\hline $\begin{array}{l}\text { *Postcode location of } \\
\text { general practice(s) }\end{array}$ & $\begin{array}{l}\text { \% Of allocations } \\
\text { ( } n=559 \text { allocations) }\end{array}$ \\
\hline L4 & 5 \\
L5 & 2 \\
L6 & 11 \\
L7 & 19 \\
L8 & 48 \\
L13 & 6 \\
L15 & 4 \\
L17 & 2 \\
L19 & 2 \\
L24 & 1 \\
\hline & *Every residential or business addresses in the UK \\
has a full postcode of the form "L18 3NA", the \\
first part of which indicates the postcode district \\
(in this case the Liverpool postcode district "L18").
\end{tabular}

2000, Liverpool Health Authority (LHA) made 559 allocations (each allocation involves one or more asylum seekers) to GPs. Although this is only a subset of the total number of asylum seekers in Liverpool, it does give us an indication of the relative caseload in individual GP practices in different parts of Liverpool (table 1).

(4) Lack of adequate number of qualified interpreters

The asylum seekers come from different countries, between them the asylum seekers (in Liverpool) speak more than 20 different languages/dialects. Communication with nonEnglish speaking asylum seekers is the biggest problem. This is further complicated by the fact that the Home Office letters do not state what language(s)/dialects the asylum seeker(s) speak. The local interpreting service is expanding, but the availability of interpreters, for example Czech, does not reflect the proportion of non-English speaking Czech asylum seekers. Additionally, no one has a complete database of the asylum seekers coming into the city, or knowledge of who is coming when and to where.

(5) Lack of information about the health status of the asylum seekers.

The acute consultation or unexpected visit to a GP practice is the most difficult to deal with, as health workers have to explore if they are registered elsewhere. This can entail ringing a number of health authorities/practices and is very time consuming. We are aware that a number of asylum seekers have been screened at port of entry, or treated by GPs in those areas, and this information does not reach receiving health authorities.

\section{ARE THERE LESSONS FROM THE EXPERIENCE WITH KOSOVAN REFUGEES?}

The health authority and North Mersey Community (NHS) Trust (NMCT) liaised with Manchester Health Authority, and Manchester Airport, to ensure that urgent health needs were identified and met during the arrival of the Kosovan refugees at Manchester Airport and during transfer to Liverpool. The Consultant in Communicable Disease Control has made regular contact with the Regional Health Emergency Planning Advisor, Department of Health, Communicable Disease Surveillance Centre and other UK centres where refugees have been placed. This joint working has ensured rapid dissemination of nationally produced information (specific advice on immunisation, infection control, communicable diseases, etc), guidance, and recommendations to the professionals providing services for the Kosovan refugees.

In total 272 Kosovan Refugees arrived in May and June 1999 in Liverpool; 120 refugees arrived on 21 May, followed by the second and third groups of 80 and 72 refugees, who 


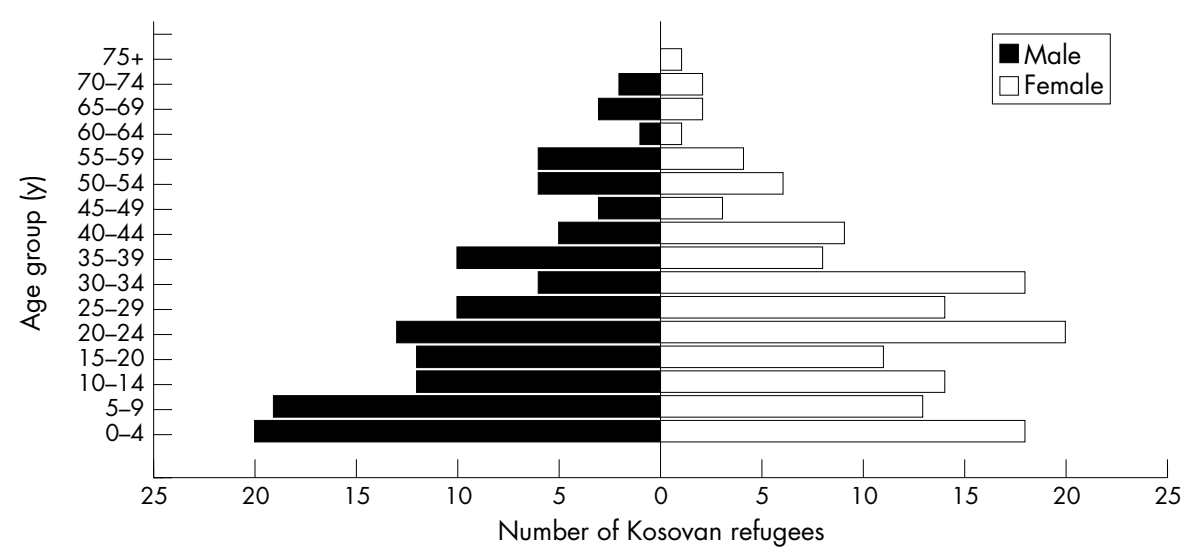

Figure 3 Age and sex breakdown of Kosovan refugees, Liverpool $(n=272)$.

arrived on the 1 June and 14 June 1999 respectively. The majority of the Kosovan refugees were under the age of 40 years $(81 \%)$, children (0-14 years) and the elderly (65 and above) account for about $36 \%$ and $4.0 \%$ respectively. The age and sex breakdown of the total Kosovan refugees is presented in figure 3.

Within two weeks of their arrival almost all (266 of 272 $(98 \%))$ of the Kosovan refugees were registered with GPs in Liverpool. Services for the refugees were provided both at the reception centres and the respective general practices. During the first week a team of GPs, district nurses, practice nurses, health visitors, dentists and tuberculosis control nurses, were available at the reception centres to provide immediate primary care and establish appropriate medical record systems. The health needs of the Kosovan refugees were assessed systematically using questionnaires developed by Leeds and Morecambe Bay Health Authorities.

The Communicable Disease Surveillance Centre (CDSC) has published an assessment of communicable disease hazards facing the refugees. ${ }^{5}$ The CDSC recommended to offer the Kosovan refugees the full UK schedule of immunisation, and to screen on arrival for tuberculosis. Tuberculosis is an expensive disease and it is probable that simple but comprehensive approaches to surveillance and screening will prove to be highly cost effective, especially in populations that have a high incidence of the disease, as is the case with population of new immigrants. ${ }^{6}$ All the Kosovan refugees in Liverpool were offered screening for tuberculosis (table 2).

In general, it was possible to provide a relatively comprehensive and coordinated response for the Kosovan refugees for following reasons:

(1) The commitment from the UK government to provide services based on respect for fundamental human rights and the spirit of the UN convention, ${ }^{1}$ and the 1967 protocol on the status of refugees. ${ }^{7}$ The leadership and commitment from the central government was important in ensuring that the administrative system functioned to meet the needs of the Kosovan refugees. ${ }^{8}$

(2) Central allocation of resources (Home Office), plus providing benefits in cash, not in kind.

(3) The scheme was voluntary unlike the dispersal programme: very few Kosovan refugees (less than 1\%) moved to London despite the presence of a large Kosovan community in London.

(4) Prior notification of the number of Kosovan refugees coming to the city.

(5) The Kosovan refugees were coming through one route and one route only, and this helped to identify the total number of arrivals in the city, and to plan services.

(6) Sympathetic media coverage that helped to shape public opinion favourably.

Table 2 Screening for tuberculosis-Heaf test results, Kosovan Refugees, Liverpool

\begin{tabular}{|c|c|c|c|c|c|c|c|c|}
\hline \multirow{2}{*}{$\begin{array}{l}\text { Reception } \\
\text { centre }\end{array}$} & \multirow{2}{*}{$\begin{array}{l}\% \text { Of refugees } \\
\text { screened }\end{array}$} & \multicolumn{7}{|c|}{ Heaf test results } \\
\hline & & Grade* 0 & Grade 1 & Grade 2 & Grade† 3 & Grade† 4 & Grade 5 & Not read \\
\hline A & $118 / 120(98)$ & $31(26)$ & $21(18)$ & $43(36)$ & $18(14)$ & $5(4)$ & $0(0)$ & $2(2)$ \\
\hline B & $134 / 152$ (88) & 25 (19) & 17 (13) & $51(38)$ & $33(25)$ & 1 (1) & $0(0)$ & $5(4)$ \\
\hline Total & $252 / 272$ (93) & $56(22)$ & 38 (15) & 94 (37) & $51(20)$ & $6(3)$ & $0(0)$ & $7(3)$ \\
\hline
\end{tabular}

*All offered BCG vaccination; †all referred to TB clinic and discharged after clear chest radiograph results, four (1.5\%) had been given prophylaxis.

Table 3 Differences between the Kosovan refugees and asylum seekers

\begin{tabular}{lll}
\hline & Kosovan refugees & Asylum seekers \\
\hline Initiative to come to the UK & UK government & Individual \\
Status & Leave to remain in the UK (for 12 months in the first instance) & Asylum seekers \\
Political support & Support by most parties in the UK and the EU & Support varies between political parties \\
Origin & Former Yugoslavia & Ranges from Somalia to China \\
Proximity to the West & Very close & Varies \\
Benefits/support & Adequate & Limited \\
& Home Office: cash & Home Office NASS Directorate: "Cash less" Voucher System \\
Media image & Positive = sympathetic, supportive & Negative = stereotyping \\
Public attitude & Favourable & Mixed \\
\hline
\end{tabular}


(7) All the Kosovan refugees were from the same region, speaking the same language with similar social background.

It could be argued that all or most of the above factors could not be applied to the asylum seekers, as their circumstances are different from the Kosovan refugees. We are aware that there are major differences between the Kosovan refugees and asylum seekers not least the way the Balkan war was covered by the media in the UK compared with wars in other regions, for example, the recent war between Ethiopia and Eritrea. Table 3 presents some of the perceived differences between the Kosovan refugees and asylum seekers.

\section{RECOMMENDATIONS FOR IMPROVING PRESENT ARRANGEMENTS FOR ASYLUM SEEKERS}

It is possible to provide a service similar if not better than that provided for Kosovan refugees. Firstly, there needs to be a strong commitment from the government to providing services based on respect for human rights. This should include raising public awareness of the specific needs of refugees and asylum seekers as people who are vulnerable to discrimination and subject to disadvantage because of their experience of exile, and to challenge stereotypes and misinformation about refugees and asylum seekers. Recently, the Audit Commission analysed 161 local press articles published in October/November 1999, and only 6\% cited the positive contribution made by asylum seekers and refugees. ${ }^{2}$ Secondly, resources should follow asylum seekers. Thirdly, the current system of dispersing asylum seekers through different routes should be discontinued. There is an urgent need for a unified system of dispersal, preferably through local authority and health authority consortiums. Fourthly, efforts need to be made to place asylum seekers in areas where there are existing minority communities. The Kosovan refugees came as family groups in the main. They had, therefore, psychological support from one another. On the other hand, the dispersed asylum seekers' population is constituted of many single young men and women who are almost certainly alone. In addition to mental and psychological wellbeing, this has implications for providing care, support (including interpretation services) and accommodation. Finally, there is a need for a secured national database of asylum seekers. This database should be made accessible by all relevant agencies. NASS has a database with an identification number for each asylum seeker. However, possibly because of concerns about confidentiality, NASS is not willing to share or allow appropriate access by other agencies to their database.

The present trend indicates that the number of asylum seekers arriving in the UK will increase over the coming years, and it is therefore opportune to make changes to the present arrangements. The recognition of the humanitarian crisis presented by the Balkan war by the international community including the UK resulted in a decisive implementation of an

\section{Key points}

- The approach used for providing care, support and accommodation for the Kosovan refugees was successful.

- The current support arrangements available for asylum seekers are inadequate.

- There needs to be a commitment from the government to providing service based on respect for human rights.

- The dispersal of asylum seekers in an ad hoc and uncoordinated fashion should be discontinued. There is an urgent need for a unified system of dispersal, preferably through local authority and health authority consortiums.

- There is a need for a secured and accessible national database of asylum seekers.

- Additional resources are required to meet the needs of asylum seekers.

emergency plan to assess the Kosovan people. This emergency response now provides a model for a new holistic strategic response to ensure that necessary services are adequately provided and based on respect for fundamental human rights in the spirit of the UN convention ${ }^{1}$ and the 1967 protocol on the status of refugees.

\section{ACKNOWLEDGEMENTS}

We acknowledge the important contributions to this paper of Hilary Grant, Regional Manager-Asylum Seekers, North Mersey Community (NHS) Trust.

Conlicts of interest: none.

\section{Authors' affiliations}

S Ghebrehewet, M Regan, Liverpool Health Authority, UK

L Benons, Bury and Rochdale Health Authority, UK

J Knowles, North Mersey Community (NHS) Trust, UK

\section{REFERENCES}

1 Immigration and Asylum Act 1999. London: Stationery Office, 2000 (www.hmso.gov.uk/acts/acts 1999/19990033.htm)

2 Audit Commission Briefing. Another Country: Implementing dispersal under the immigration and Asylum Act 1999. June 2000.

3 Aldous J, Bardsley M, Daniell R, et al. Refugee health in London: key issues for pubic health. The health of Londoners project. London: NHS Executive Thames Regional Office, 1999.

4 Ramsay R, Turner S. Refugees' health needs. Br J Gen Pract 1993;43:480-1.

5 CDSC. Communicable disease hazards facing refugees from Kosovo. CDR Weekly April 1999:9:number 17

6 Van den Bosch C, Roberts J. Tuberculosis screening of new entrants how it can be made more effective? J Public Health Med 2000;22:220-3.

7 United Nations. Convention on the status of refugees 1951. New York: United Nations, 1951. (Protocol updating the convention published in 1967)

8 Sram I, Ward D. Balkan briefing. Kosovo refugees in the North West Region of the United Kingdom. J Epidemiol Community Health 2000;54:314-17. 